\title{
Implementasi Augmented Reality pada Mata Pelajaran Komputer dan Jaringan Dasar di SMK Nufa Citra Mandiri Berbasis Android
}

\author{
Bobi Agustian ${ }^{1}$, Muhamad Yasser Arafat ${ }^{2}$ \\ ${ }^{1,2}$ Teknik Informatika, Universitas Pamulang, Serpong, Tangerang Selatan, Banten, Indonesia, \\ 15310 \\ e-mail: ${ }^{1}$ dosen00679@unpam.ac.id, ${ }^{2}$ dosen00680@unpam.ac.id \\ Submitted Date: December $10^{\text {th }}, 2020$ \\ Revised Date: January $01^{\text {st }}, 2021$ \\ Reviewed Date: December $31^{\text {st }}, 2020$ \\ Accepted Date: January $05^{\text {th }}, 2021$
}

\begin{abstract}
In the process of teaching and learning activities in schools, there are still many that only use learning media in the form of books. This causes boredom in the learning process. Especially in basic computer and network subjects, where in this subject there is a lot of visual recognition and developing forms of technology. Good visual presentation is very important to support the learning process. Augmented Reality (AR) is a learning medium that is currently still being used in the teaching and learning process. AR is an application that combines the real world with the virtual world in two-dimensional or three-dimensional forms which are projected in a real environment at the same time. AR technology is very appropriate to be implemented to support the visualization process in learning activities, because it can present visualization in 3-dimensional form. So that the visualization is more interactive and more interesting. In the learning process at SMK Nufa Citra Mandir, they still rely on books only, especially in computer and basic network subjects which really need visualization of the devices discussed. The application of AR technology to basic computer and network subjects at SMK Nufa Citra Mandiri is expected to help in the learning process. In its development, the design method used is the Extreme Programming (XP). Purpose of this research is to create software with AR technology on Android platform, so that students can better understand and get to know computer tools and computer network devices contained in basic computer and network subjects.
\end{abstract}

Keywords: augmented reality; extreme programming; android; learning.

\begin{abstract}
Abstrak
Dalam proses kegiatan belajar mengajar di sekolah masih banyak yang hanya menggunakan media pembelajaran berupa buku saja. Hal ini menyebabkan terjadinya kejenuhan dalam proses belajar. Khususnya pada mata pelajaran komputer dan jaringan dasar, pada mata pelajaran ini banyak terdapat pengenalan visual dan bentuk teknologi yang sedang berkembang. Penyajian visual yang baik sangatlah penting untuk menunjang proses pembelajaran. Augmented Reality adalah salah satu media pembelajaran yang saat ini masih baru digunakan dalam proses belajar mengajar. Augmented reality adalah sebuah aplikasi yang menggabungkan dunia nyata dengan dunia virtual dalam bentuk dua dimensi dan tiga dimensi lalu diproyeksikan ke dalam lingkungan yang nyata dalam waktu yang sama. Teknologi augmented reality sangat tepat diimplementasikan untuk menunjang proses visualisasi dalam kegiatan pembelajaran, karena dapat menyajikan visualisasi dalam bentuk 3 dimensi. Sehingga visualisasi lebih interaktif dan lebih menarik. Dalam proses pembelajaran di SMK Nufa Citra Mandir masih mengandalkan buku saja, khususnya dalam mata pelajaran komputer dan jaringan dasar yang sangat membutuhkan visualisasi mengenai perangkat-perangkat yang dibahas. Penerapan teknologi augmented reality pada mata pelajaran komputer dan jaringan dasar di SMK Nufa Citra Mandiri diharapkan dapat membantu pada proses pembelajaran. Dalam pengembangannya metode rancang bangun yang digunakan adalah model Extreme Programming (XP). Penelitian ini memiliki tujuan untuk membuat sebuah aplikasi dengan teknologi augmented reality pada platform android, agar siswa dapat lebih memahami dan mengenal alat-alat komputer dan perangkat jaringan komputer yang terdapat pada pada mata pelajaran yang ada di SMK NCM yaitu komputer dan jaringan dasar.
\end{abstract}


Kata kunci: augmented reality; extreme programming; android; pembelajaran.

\section{Pendahuluan}

Augmented Reality yang dimaksud adalah sebuah aplikasi yang menggabungkan dunia digital atau virtual dengan dunia nyata yang berbentuk dua dimensi dan tiga dimensi lalu diproyeksikan ke lingkungan nyata pada waktu yang sama. Augmented reality biasanya diterapkan dalam sebuah aplikasi game (Mustaqim \& Kurniawan, 2017). Augmented Reality adalah suatu penggabungan beberapa benda yang terdapat di dunia virtual ke dalam dunia nyata yang berbentuk dua dan tiga dimensi yang bisa disentuh, dilihat, maupun didengar (Nurcahyo \& Hantono, 2015). Pada teknologi AR dapat juga ditambahkan beberapa informasi tertentu yang ada ke dalam dunia virtual dan bisa juga menampilkan informasinya ke dunia nyata dengan dibantu oleh beberapa perlengkapan yang ada seperti webcam, smartphone, komputer, dan bisa juga menggunakan kacamata khusus (Mauludin, Sukamto, \& Muhardi, 2017). AR bisa juga menambahkan serta melengkapi kenyataan objek virtual yang nantinya akan digabungkan ke dalam lingkungan nyata yang berfungsi sebagai media untuk menampilkan informasi yang secara langsung tidak bisa diterima oleh manusia (Ananda, Safriadi, \& Sukamto, 2015).

Pemanfaatan teknologi Augmented Reality sudah banyak juga dikembangkan di dunia pendidikan untuk media atau penunjang pembelajaran. Augmented Reality (AR) adalah merupakan sintesis perumpamaan dunia nyata dan dunia maya. Aplikasi AR sudah banyak diterapkan dalam berbagai aspek kehidupan. Bidang pendidikan adalah bidang yang paling banyak diterapkan. Augmented Reality merupakan sebuah konsep aplikasi yang menggabungkan dunia nyata dengan dunia digital atau dunia maya, tanpa mengubah suatu bentuk objek fisiknya (Atmajaya, 2017).

Pada mata pelajaran komputer dan jaringan dasar, siswa diberikan pembelajaran dasar dari beberapa pengembangan teknologi sekarang ini dan beberapa ukuran bentuk dari suatu benda teknologi tersebut seperti benda kecil, benda besar, benda murah ataupun benda mahal, bahkan penggambaran sistem pun menjadi peranan penting bagi teknologi tersebut. Penerapan teknologi pada mata pelajaran tersebut menjadi ilmu yang baik untuk pengetahuan siswa jurusan teknik komputer dan jaringan, masalah pada yang terjadi pada mata pelajaran tersebut ialah terkadang siswa sulit memahami beberapa bentuk atau visual dari macam-macam alat jaringan komputer, dikarnakan siswa hanya melihat dan membaca pada modul mata pelajaran tersebut. Sebagai contoh objek yang digunakan adalah pengenalan bentuk Router, konektor, HUB, Wifi, dan lain-lain, dimana objek-objek tersebut dapat dengan mudah di temui oleh siswa, sehingga dapat terjadi keberlangsungan pembelajaran pada siswa. Pada rancang bangun dalam pembuatan teknologi $\mathrm{AR}$ ini menggunakan model pengembangan sistem extreme programming (XP). XP adalah sebuah metode dalam proses rekayasa perangkat lunak yang menggunakan pendekatan berorientasi objek (Supriyatna, 2018).Teknologi AR juga disusun dengan tujuan untuk menampilkan informasi secara maya dan simulasi mengenai metodemetode dan pendekatan tersebut supaya para guru dapat memiliki pemahaman yang memadai dan bisa juga menyajikan pembelajaran yang lebih aktif sesuai dengan yang menjadi tuntutan implementasi kurikulum (Mantasia \& Jaya, 2016).

Tujuan dari penelitian ini adalah membuat aplikasi untuk pembelajaran siswa pada mata pelajaran komputer dan jaringan dasar di SMK Nufa Citra Mandiri (NCM), diharapkan teknologi augmented reality dari aplikasi yang dibuat tersebut dapat meningkatkan media pembelajaran interaktif dengan memanfaatkan visualisasi secara tiga dimensi untuk gambar untuk menciptakan realitas nyata pada proses pembelajaran. Tujuan lainnya adalah menyediakan media pembelajaran berbasis digital sesuai dengan arah perkembangan di masa mendatang.

\section{Metode Penelitian}

Dalam penelitian ini metode pengembangan aplikasi yang digunakan adalah Extreme Programming (XP). Extreme programming (XP) merupakan salah satu metodologi yang terdapat di dalam pengembangan agile software development methodologies yang lebih terfokus kepada proses pengkodean (coding), proses coding adalah yang menjadi aktivitas utama di dalam semua tahapan pada siklus pengembangan sebuah aplikasi (Gunawan, Napianto, Borman, \& Hanifah, 2019). Di dalam XP terdapat suatu iterasi yang dapat dilaksanakan berulang kali sesuai dengan kebutuhan. XP memberikan tahapan dengan waktu yang 554 eknik 554e singkat dan berulang untuk 
bagian-bagian yang berbeda sesuai dengan 555ekni yang nantinya akan dicapai (Borman, Priandika, \& Edison, 2020).

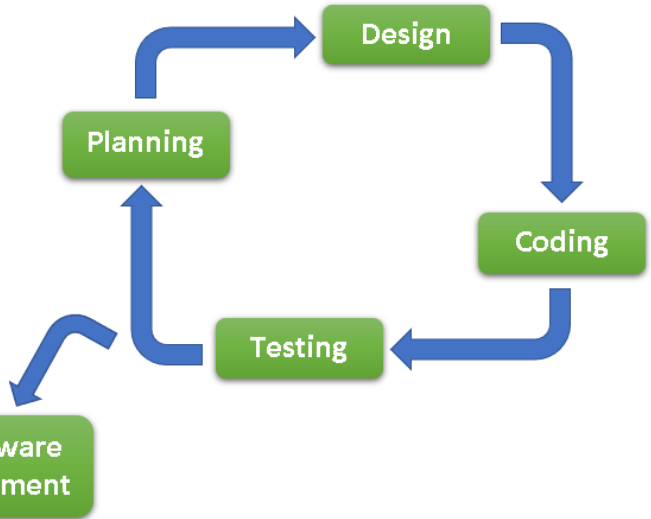

Gambar 1. Tahapan pembangunan aplikasi

Adapun tahapan pembangunan aplikasi adalah sebagai berikut:

1. Planning (Perencanaan)

Tahapan perencanaan adalah merupakan suatu tahapan yang melibatkan pengguna dalam menetukan apa saja kebutuhan yang yang ada berdasarkan hasil eksplorasi (Fatoni \& Irawan, 2019).

2. Design (Perancangan)

Dalam proses perancangan dilakukan pemodelan sistem dengan berdasarkan hasil analisa kebutuhan. Tidak hanya itu tetapi juga dibuat pemodelan basis datanya dengan tujuan untuk menggambarkan hubungan antar data. Unified Modelling Language (UML) adalah pemodelan sistem yang digunakan, yaitu terdiri dari beberapa diagram yang ada, antara lain adalah Use-Case Diagram, Component Diagram, Activity Diagram, dan Deployment Diagram. Untuk pemodelan basis datanya digunakan Entity Relationship Diagram (ERD) serta juga menggunakan Logical Record Structure (LRS).

3. Coding (Pengkodean)

Pada tahapan pengkodean akan dilakukan implementasi perancangan model sistem yang telah dirancang menjadi ke dalam sebuah kode program yang akan menghasilkan sebuah prototipe dari aplikasi.

4. Testing (Pengujian)

Setelah tahapan pengkodean selesai dilakukan, kemudian berikutnya dilakukan tahapan pengujian. Pengujian merupakan tahapan penting yang harus dilakukan untuk memberikan jaminan terhadap kualitas perangkat lunak yang dikembangkan
(Muslimin, et al., 2020). Pengujian untuk mengetahui apakah sistem yang dibuat telah sesuai dengan kebutuhan user (Carolina \& Supriyatna, 2019). Pengujian harus direncanakan dan memiliki cakupan yang lengkap, karena pengujian tidak lengkap dan efektif dapat menimbulkan masalah dan menyebabkan kerugian ketika software digunakan (Rosalina, Rassi, Hadi, Ubaidillah, \& Desyani, 2020).

5. Software Increment (Peningkatan Perangkat Lunak)

Pada tahapan peningkatan perangkat lunak akan dilakukan pengembangan sistem yang sudah dibuat dengan cara bertahap yang akan dilakukan Ketika sistem telah diterapkan ke dalam sebuah organisasi dengan menambahkan konten atau layanan sehingga memperkaya kemampuan fungsi sistem tersebut (Supriyatna, 2018).

\section{Metode pengumpulan data}

tiga, yaitu:

Metode pengumpulan data yang digunakan ada

a. Studi Lapangan (Observasi)

Peneliti mengumpulkan data di lapangan dengan cara melakukan pengamatan secara langsung terhadap pembelajaran mata pelajaran komputer dan jaringan dasar di SMK Nufa Citra Mandiri.

b. Wawancara (Interview)

Peneliti melakukan wawancara dengan pihakpihak terkait, seperti pihak kpala sekolah, guru dan siswa, kemudian mencatat semua keterangan yang didapat kedalam salinan interview dan medokumentasikan berupa fotofoto.

\section{c. Studi Pustaka (Literatur)}

Peneliti mengumpulkan data dari literatur-literatur yang berhubungan dengan penelitian yang dilakukan, seperti modul-modul pembelajaran, jurnal, buku - buku referensi, website,dan studi literatur lainnya.

\section{Hasil dan Pembahasan}

Pada penelitian ini menghasilkan suatu aplikasi augmented reality berbasis android yang dapat digunakan sebagai media dalam membantu proses pembelajaran dalam mata pelajaran 555eknik komputer jaringan. Pada aplikasi yang dibuat terdapat menu untuk memvisualisasikan perangkat jaringan komputer dalam bentuk tiga dimensi. 


\subsection{Visualisasi Router}

Untuk menampilkan visualisasi secara tiga dimensi dibutuhkan marker untuk di scan sehingga menampilkan objek tiga dimensi yang ingin ditampilkan

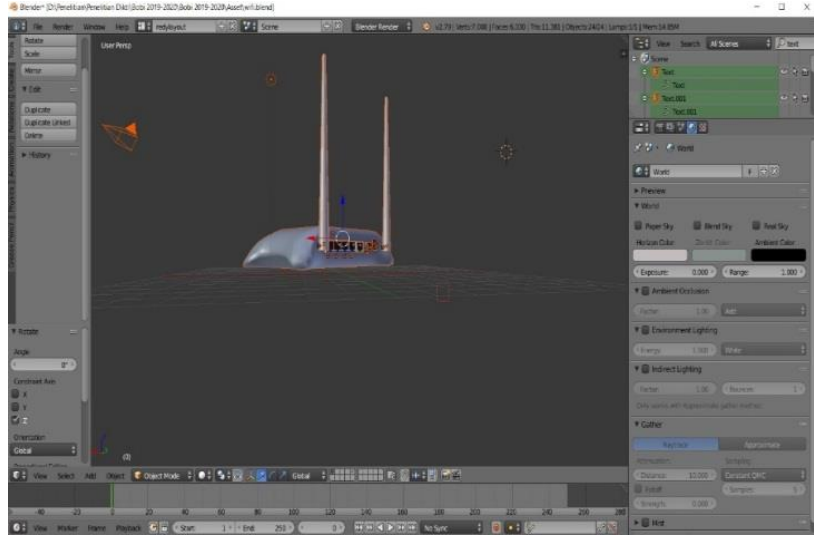

Gambar 2. Visualisasi router

Gambar diatas adalah gambar yang digunakan untuk memvisualisasikan perangkat keras atau yang biasa disebut dengan istilah hardware. Perangkat keras diatas adalah router, yaitu suatu perangkat keras yang berfungsi sebagai penghubung beberapa jaringan, baik jaringan yang sama maupun berbeda dari sisi teknologinya.

\subsection{Visualisasi Hub}

Berikut adalah tampilan visualisasi tiga dimensi perangkat hub.

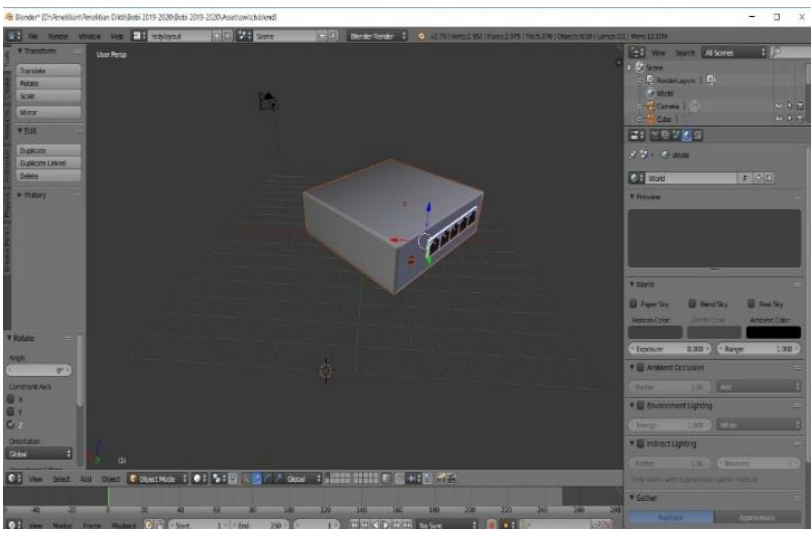

Gambar 3. Visualisasi hub

Diatas adalah gambar untuk memvisualisasikan perangkat keras berupa hub. Hub adalah adalah perangkat keras jaringan yang berfungsi sebagai penghubung beberapa perangkat bersama-sama dan menjadikannya bertindak sebagai segmen jaringan tunggal.

\subsection{Visualisasi Crimping Tools}

Berikut adalah tampilan visualisasi tiga dimensi perangkat crimping tools.

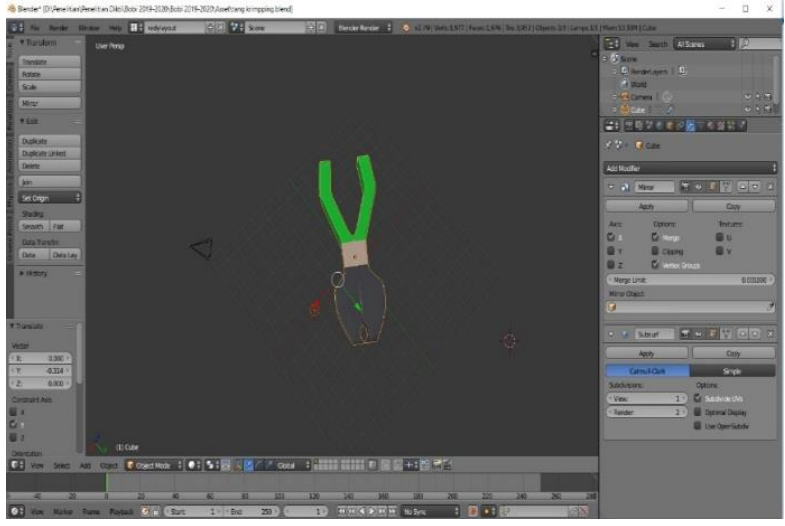

Gambar 4. Visualisasi crimping tools.

Gambar berikutnya adalah crimping tools. Crimping tools merupakan suatu perangkat keras yang dapat digunakan untuk membantu dalam proses perangkaian kabel jaringan.

\subsection{Visualisasi Kabel UTP dan Konektor RG 45}

Berikut adalah tampilan visualisasi tiga dimensi perangkat kabel UTP dan konektor RG 45.

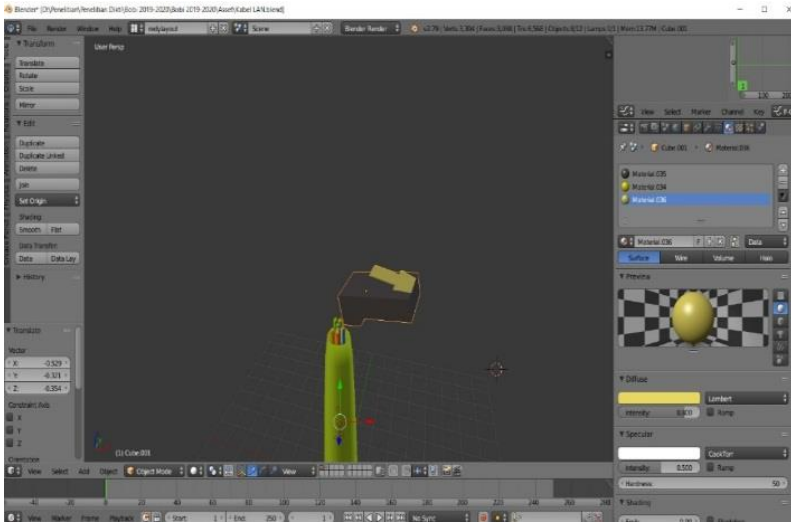

Gambar 5. Visualisasi kabel UTP dan konektor RG 45

Gambar di atas adalah perangkat keras yang merupakan suatu media dalam jaringan. Kabel UTP merupakan salah satu kabel yang biasa dipakai sebagai media penghubung dalam jaringan komputer.

\section{Kesimpulan}

Penerapan Augmented Reality sangat berguna sebagai media pembelajaran yang interaktif bagi peserta didik. Tidak hanya itu tetapi media pembelajaran yang mengaplikasikan 
Augmented Reality juga dapat meningkatkan minat peserta didik dalam belajar karena kemampuan visualisasinya yang lebih menarik sehingga dapat meningkatkan daya imajinasi para peserta didik. Augmeneted Reality juga memiliki sifat yang lebih interaktif yang dapat membuat peserta didik untuk bisa melihat keadaan secara nyata dan juga dapat mengimajinasikan hasil proses pembelajaran yang diberikan pendidik kepada peserta didik.. Media Pembelajaran Augmented Reality dapat memberikan visualisasi perangkat-perangkat jaringan yang disebutkan dalam proses pembelajaran mata pelajaran komputer dan jaringan dasar di SMK Nufa Citra Mandiri. Pada bagian ini, penulis memberi pernyataan mulai dari apa yang diharapkan dari penelitian, yang ditulis pada bagian "Pendahuluan", sampai dengan hasil yang diperoleh pada bagian "Hasil dan Pembahasan", sehingga menjadi sebuah kesatuan yang dapat dijelaskan secara singkat, padat, dan jelas. Pada bagian ini juga dapat ditambahkan mengenai rencana penelitian berikutnya berdasarkan hasil yang diperoleh.

\section{Daftar Pustaka}

Ananda, T. A., Safriadi, N., \& Sukamto, A. S. (2015). Penerapan Augmented Reality sebagai PlanetPlanet di Tata Surya. Jurnal Sistem dan Teknologi Informasi, 1(1), 1-6.

Atmajaya, D. (2017). Implementasi Augmented Reality untuk Pembelajaran Interaktif. ILKOM Jurnal Ilmiah, 9(2), 227-232.

Borman, R. I., Priandika, A. T., \& Edison, A. R. (2020). Implementasi Metode Pengembangan Sistem Extreme Programming (XP) pada Aplikasi Investasi Peternakan. JUSTIN (Jurnal Sistem dan Teknologi Informasi), 8(3), 272-277.

Carolina, I., \& Supriyatna, A. (2019). Penerapan Metode Extreme Programming dalam Perancangan Aplikasi Perhitungan Kuota Sks Mengajar Dosen. IKRA-ITH INFORMATIKA : Jurnal Komputer dan Informatika, 3(1), 106-113.

Fatoni, \& Irawan, D. (2019). Implementasi Metode Extreme Programming dalam Pengembangan Sistem Informasi Izin Produk Makanan. Jurnal Sisfokom (Sistem Informasi dan Komputer), 8(2), 159-164.

Gunawan, R. D., Napianto, R., Borman, R. I., \& Hanifah, I. (2019). Penerapan Pengembangan Sistem Extreme Programming pada Aplikasi Pencarian Dokter Spesialis di Bandar lampung Berbasis Android. Format : Jurnal Ilmiah Teknik Informatika, 8(2), 148-157.

Mantasia, \& Jaya, H. (2016). Pengembangan Teknologi Augmented Reality sebagai Penguatan dan Penunjang Metode Pembelajaran di Smk Untuk
Implementasi Kurikulum 2013. jurnal pendidikan vokasi, 6(3), 281-291.

Mauludin, R., Sukamto, A. S., \& Muhardi, H. (2017). JEPIN (Jurnal Edukasi dan Penelitian Informatika), 3(2), 117-123.

Muslimin, D. B., Kusmanto, D., Amilia, K. F., Ariffin, M. S., Mardiana, S., \& Yulianti, Y. (2020). Pengujian Black Box pada Aplikasi Sistem Informasi Akademik Menggunakan Teknik Equivalence Partitioning. Jurnal Informatika Universitas Pamulang, 5(1), 19-25. doi:10.32493/informatika.v5i1.3778

Mustaqim, I., \& Kurniawan, N. (2017). Pengembangan Media Pembelajaran Pai Berbasis Augmented Reality. Jurnal Edukasi Elektro, 1(1), 36-48.

Nurcahyo, D. E., \& Hantono, B. S. (2015). Pemanfaatan Augmented Reality dalam Dunia Pendidikan untuk mempelajari Anatomi Tubuh Manusia Berbasis Android. Jurnal Seminar Nasional Teknologi Informasi dan Komunikasi 2015 (SENTIKA 2015), 2015(25), 193-198.

Rosalina, A., Rassi, A. A., Hadi, G. Y., Ubaidillah, R., \& Desyani, T. (2020). Pengujian Black Box pada Sistem Informasi Penjualan HI Shoe Store Menggunakan Teknik Equivalence Partitions. Jurnal Informatika Universitas Pamulang, 5, 26-29. doi:10.32493/informatika.v5i1.3964

Supriyatna, A. (2018). Metode Extreme Programming pada Pembangunan Web Aplikasi Seleksi Peserta Pelatihan Kerja. Jurnal Teknik Informatika, 11(1), 1-18. 